\title{
Evaluating rheological properties and recovery performance of polymeric anionic surfactant (PSURFC) synthesized from non-edible seed oil on heavy crude recovery
}

\author{
Ojo Temiloluwa' ${ }^{1}$. Oguntade Tomiwa ${ }^{1} \cdot$ Oni Babalola $^{2}$
}

Received: 28 November 2019 / Accepted: 21 May 2020 / Published online: 30 May 2020

(c) The Author(s) 2020

\begin{abstract}
This research focuses on heavy crude recovery using the dual recovery process of macromolecules formulated from environmentally friendly seed oil and polymer (Xanthan gum) with both hydrophobic and hydrophilic properties. The inexpensive, non-toxic polymeric surfactant (PSURFC) is synthesized through free radical polymerization technique involving novel non-edible seed oil surfactant and xanthan gum. Rheology shows a shear-thinning behavior at room temperature indicates an improvement in the rheology on surfactant addition to the mixture. As a macromolecule, PSURFC combines dual oil recovery nature in a single component thereby influencing interfacial tension (IFT) and mobility ratio simultaneously. Its performance during enhanced oil recovery (EOR) was evaluated through core flooding, scanning electron microscopy (SEM), IFT and rheology. EOR was conducted using OFITE®'s reservoir permeability tester (RPT) as the core flooding apparatus on five set of Berea sandstone core samples. Its implementation in EOR improved oil recovery when compared with water flooding, surfactant and polymer flooding. Sequel to the conventional water flooding, efficiency of PSURFC gave additional recoveries of $54 \%, 60 \%$ and $70 \%$ of the initial oil in place. This result validates the ability of polymeric surfactant to effectively mobilize residual oil under typical sandstone reservoir conditions.
\end{abstract}

Keywords Enhanced oil recovery · Anionic surfactant flooding · Interfacial tension · Polymeric surfactant · Polymer flooding $\cdot$ Reservoir permeability tester (RPT)

\section{Introduction}

Once an oil field is discovered, oil is usually mobile into a producing well under the natural pressure of the fluids existing in the porous reservoir rocks. However, pressure decline occurs during continuous oil production from reservoir. Several considerations have shown that primary and secondary oil recovery process cannot mobilize all trapped reservoir oil. Utilization of different combinations of EOR methods is gradually becoming a trend for Oil recovery processes (Alvani and Jouyban 2019; Ojo and Fadairo 2017).

Ojo Temiloluwa

temiloluwa.ojo@covenantuniversity.edu.ng

1 Reservoir Engineering Laboratory, Department of Petroleum Engineering, Covenant University, Ota, Nigeria

2 Department of Chemical Engineering, Covenant University, Ota, Nigeria
Polymer flooding appears as a good alternative method to reduce water production by improving immobility thereby achieving better-swept efficiency (Agrawal and Satapathy 2019). In sandstone reservoirs, the application of polymer flooding already proved to be an important enhanced oil recovery method because it has improved sweep efficiency when added to water (Coolman and Alexander 2020). In addition, the most polymer flooding exhibits low interfacial tension with regard to the oil phase, provides complete solubility and good mobility control (Al-Manasir and Kjøniksen 2009). The addition of polymer increases fluids viscosity, and a more favorable mobility ratio is achieved. The polymer is used to increase the viscosity of the water, while the surfactant acts as emulsifier. The mechanism of enhanced recovery involved in polymer flooding is based on decreasing the mobility difference between displacing and displaced fluids, in order to reduce fingering effects. The displacing phase should have mobility equal to or lower than the mobility of the oil phase (Mozaffari and Tchoukov 2015). The mechanism of enhanced recovery involved in 
polymer flooding is based on decreasing the mobility difference between displacing and displaced fluids, in order to reduce fingering effects (Mozaffari and Li 2018). The displacing phase should have mobility equal to or lower than the mobility of the oil phase (Ezell and McCormick 2007; Rashidi and Keimanesh 2010). However, several categories of polymers (water soluble) have been reviewed and are commonly classified into two categories: synthetic and biopolymer. One of non-ionic biopolymers is Xanthan gum it have been effectively applied in the oil recovery as a recovery agent and drilling mud (Coolman and Alexander 2020).

In surfactant flooding, chemical slug usually undergoes fingering into the oil/water bank, introduction of polymer mix, and the mobility is controlled, preventing chemical slug which form viscous fingering (Samanta and Ojha 2011, Temiloluwa and Adesina 2017). Surfactant flooding recovery mechanism is based on lowering the interfacial tension between the two phases (IFT). The role of IFT in oil recovery is better explained in terms of capillary number $(\mathrm{Ca})$ (Hirasaki et al. 2013; Bera and Belhaj 2016).

Souayeh et al. (2014) researched on the capacity of lipopeptide surfactant that was produced from Bacillus subtillis W19 that was isolated from oil from the Omani oil field (contaminated oil) to be able to bring to recovery some of the residual oil even at a reduced concentration. As predicted, the surfactant was able to cause reduction up to $1.8 \mathrm{mN} / \mathrm{m}$ in the interfacial tension and also successfully tamper with the wettability of the system to make it become neutral.

The oil immobile in the reservoir is swept from every direction both vertically and aerially during polymeric surfactant flooding (Lee and Koopal 1996). An increased viscosity derived from the increase in molecular weight is desired in polymeric surfactant flooding (LuukKoopal 1995).

The existence of polymeric surfactant (PSURFC) in polar head group gives it a functionality that is relative (Mahfud and Agag 2013; Rabiei and Sharifinik 2013). The application of this biopolymers (xanthan gum) from laboratory experiments in high salinity brine has behaved positively and well-suited with several injected co-flu id extracts for EOR processes (Orodu and Afolabi 2019). Adsorption of surfactant on Berea sandstone due to surfactant degradation and precipitation overtime has reduced its effectiveness, and this has necessitated its combination with polymer to achieve better sweep efficiency and achieving ultra-low IFT (Saxena and Saxena 2019; Saxena and Kumar 2018).

Definite failures existed in water flooding, immiscible gas flooding and surfactant flooding processes mostly as a result of the less viscous displacing fluid bypassing the more viscous oil employing mobility control agent is significant in guaranteeing the success of a displacement process (Awang and Seng 2008; Temiouwa and Oluwaanmi
2018). Viscosity enhancement, long stability, functional group with multiple nature and biodegradability has distinguished bio-based polymeric surfactant from traditional surfactants, which has small molecules (Ma and Hao 2019; Hanamertani 2017). The formulation of surfactant polymer or surfactant-alkaline polymer systems has improved interfacial activity, solubilization of polymer and emulsification crude oil (Banerjee and Kumar 2015). However, the search for solution to the emerging EOR problems from polymer flooding, surfactant-polymer flooding and other processes is ongoing (Mahfud and Agag 2013).

The injection of polymer, surfactant, nanoparticle or its combination is chemical-enhanced oil recovery (EOR) techniques which has become the most promising techniques for efficient recovery of oil (Alvani and Jouyban 2019). The application of biopolymers like xanthan gum has verified to act fine in high salinity brine and wellsuited with injected fluid blend for EOR processes. A combination of Xathan with anionic surfactant makes a good recovery agent (Chen and Zhang 2013). Besides its salinity resistance, new procedures have been stated which advances the stability of biopolymers up to $105^{\circ} \mathrm{C}$ (Orodu and Afolabi 2019).

In EOR processes which combines the two mentioned mechanisms (SP or ASP flooding), some factors should be considered, such as interactions between polymer and surfactant, loss of surfactant through solubilization in the oil phase or adsorption on the rocks and chromatographic separations of the various components, which could be detrimental for the whole process (Awang and Seng 2008; Belhaj and Elraies 2020). EOR processes involving surfactant, polymer and polymeric surfactants are chemically formulated, and they lower the interfacial tension (IFT) between displacing fluid (water) and crude oil stuck in the reservoir due to high capillary forces after the primary and secondary recovery. The rock surface wettability is influenced from oil wet to water wet and control of mobility to increase oil mobilization from water-flooded reservoir (Temiloluwa and Adesina 2017). To overcome the fault of solutions of conventional polymers and surfactant, preparation of chemically cross-linked surfactant has recently attracted interest. The idea is that polymer blend with the

Table 1 Physical properties of core samples saturated at pressure 2000psi

\begin{tabular}{llll}
\hline Sample & Pore volume $(\mathrm{cc})$ & Porosity $(\%)$ & Permeability $(\mathrm{mD})$ \\
\hline Core A1 & 17.9 & 28 & 292 \\
Core B & 16.4 & 27 & 180 \\
Core C & 19.0 & 27 & 184 \\
Core D & 9.0 & 16 & 230 \\
Core E & 10.9 & 31.4 & 92 \\
Core G & 11.5 & 31.4 & 97 \\
\hline
\end{tabular}




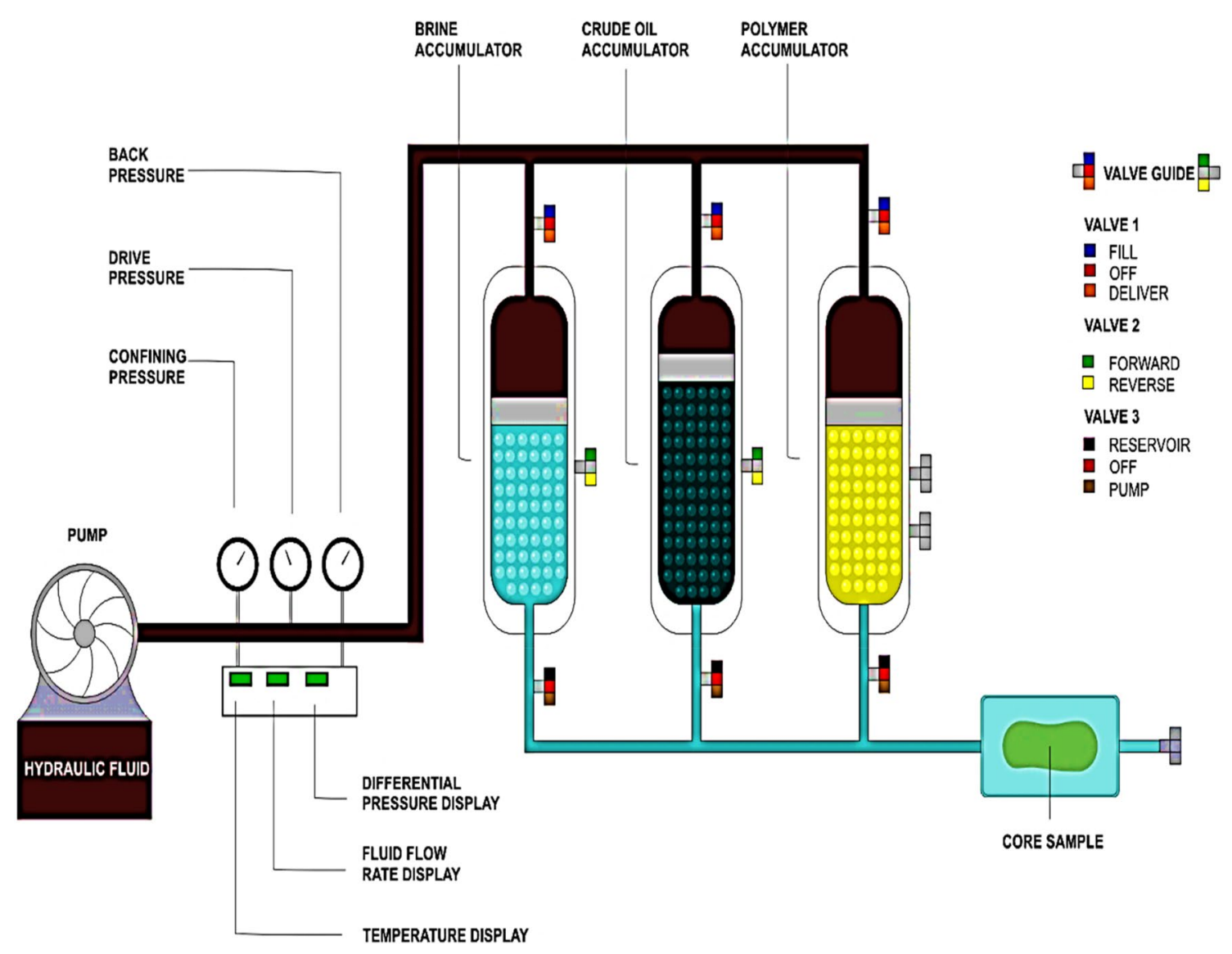

Fig. 1 Schematic of the experimental core flood (Ojo and Fadairo 2017). Experimental setup of the core flooding apparatus. pump fluid, pump, valves, displacing reservoir fluid, piston to separate the oils,

Table 2 Physicochemical properties of jatropha oil

\begin{tabular}{ll}
\hline Property & Value \\
\hline Acid value (mg KOH / g of oil) & 6.04 \\
Color & Golden yellow \\
Odor & Unpleasant \\
$\mathrm{pH}$ & 6.34 \\
Saponification value (mg KOH / g of oil) & 198.69 \\
Specific gravity & 0.92 \\
Viscosity at room temperature (cp) & 36 \\
\hline
\end{tabular}

Table 3 Compositions of surfactants utilized in surfactant flooding

\begin{tabular}{lllll}
\hline Sample & $\begin{array}{l}\text { Volume of } \\
\text { surfactant }(\mathrm{ml})\end{array}$ & $\begin{array}{l}\text { Volume of } \\
\text { water }(\mathrm{ml})\end{array}$ & $\begin{array}{l}\text { Concentra- } \\
\text { tion }(\mathrm{ppm})\end{array}$ & $\mathrm{pH}$ \\
\hline Surfactant, conc 3 & 1.0 & 100 & 10,000 & 7.9 \\
Surfactant, conc 2 & 1.5 & 100 & 15,000 & 7.7 \\
Surfactant, conc 1 & 2.0 & 100 & 20,000 & 7.5 \\
\hline
\end{tabular}

crude oil, brine, Polymer (Treating fluid), pressure gauge, bypass valve, Hassler cell holder with core, sleeve pressure and effluent into test tubes surfactant is to act as a single chemical component acting as a piston-like displacement and also breaking bond between reservoir fluids within the pores in the oil reservoir and thereby improve the displacement of the oil.

The features of such polymers are very high molecular weight, resistance to mechanical degradation in shear and, of course, complete solubility in water. Additionally, they should be inexpensive, non-toxic and able to tolerate high salinity and high temperatures (Radnia and Rashidi 2018). The polymeric systems traditionally employed for EOR have been extensively reviewed recently (Wever et al. 2011). For these reasons, the possibility to combine the positive effects of polymer and surfactants in only one component, namely a polymeric surfactant, becomes an attractive alternative for the traditional EOR processes. Indeed, the potential of polymeric surfactants for EOR has been often claimed.

This research is aimed at evaluating the recovery potential of a novel bio-based polymeric surfactant (PSURFC) on heavy crude for advances in enhanced oil recovery. 


\section{Materials}

Brine was prepared using laboratory-grade sodium chloride $[\mathrm{NaCl}]$ and acetone $\left[\mathrm{C}_{3} \mathrm{H}_{6} \mathrm{O}\right]$ for core cleaning. Core samples serve as the porous medium for measuring oil recovery were gotten from Offshore Depobelt - Niger Delta were acquired for core flooding. Berea sandstone cores were purchased from Cleveland Quarries Inc. Other materials are crude oil of $21.97{ }^{0} \mathrm{API}$ from the Niger Delta (Izombe Oilfield, OML 124), Polymer (Xanthan gum), SURFC (Jatropha).

The equipment used for core flooding and viscosity is OFITE®'s reservoir permeability tester (RPT) for the core flooding process, while OFITE®'s direct indicator viscometer (8-speed) was used for rheology studies. The core sample was saturated using Vinci Equipment's high-pressure core saturator for porosity studies. Crude oil measurement was validated using pycnometer, and core cleaning was done using Soxhlet apparatus.

Before petro-physical properties were measured, the samples to be used were washed in a solvent (acetone) in a Soxhlet apparatus to remove residual mineral oils and precipitated salt and organic minerals. It also went through a heating process in an oven at a fixed temperature. Porosity via pore volume was computed using a manual saturator and reported in Table 1 . Fluid density and viscosity were measured with pycnometer and glass capillary viscometer.

The setup procedure in Fig. 1 shows the schematic diagram for the flow system; it is a crucial experimental procedure to test the reaction of reservoir fluid on core samples
Fig. 2 Shear stress vs. shear rate analysis for Xanthan gum. Experimental condition: concentration@0.2wt\% and PSURFC concentration 1[@ $0.2 \mathrm{wt} \%$ Xanthan and $0.5 \mathrm{wt} \%$ surfactant]. Temp at $28{ }^{\circ} \mathrm{C}$

Fig. 3 Shear stress vs. shear rate analysis for Xanthan gum. Experimental condition: concentration@0.3wt\% and PSURFC concentration 2 [@ $0.3 \mathrm{wt} \%$ Xanthan and $0.5 \mathrm{wt} \%$ surfactant]. Temperature at $28{ }^{\circ} \mathrm{C}$
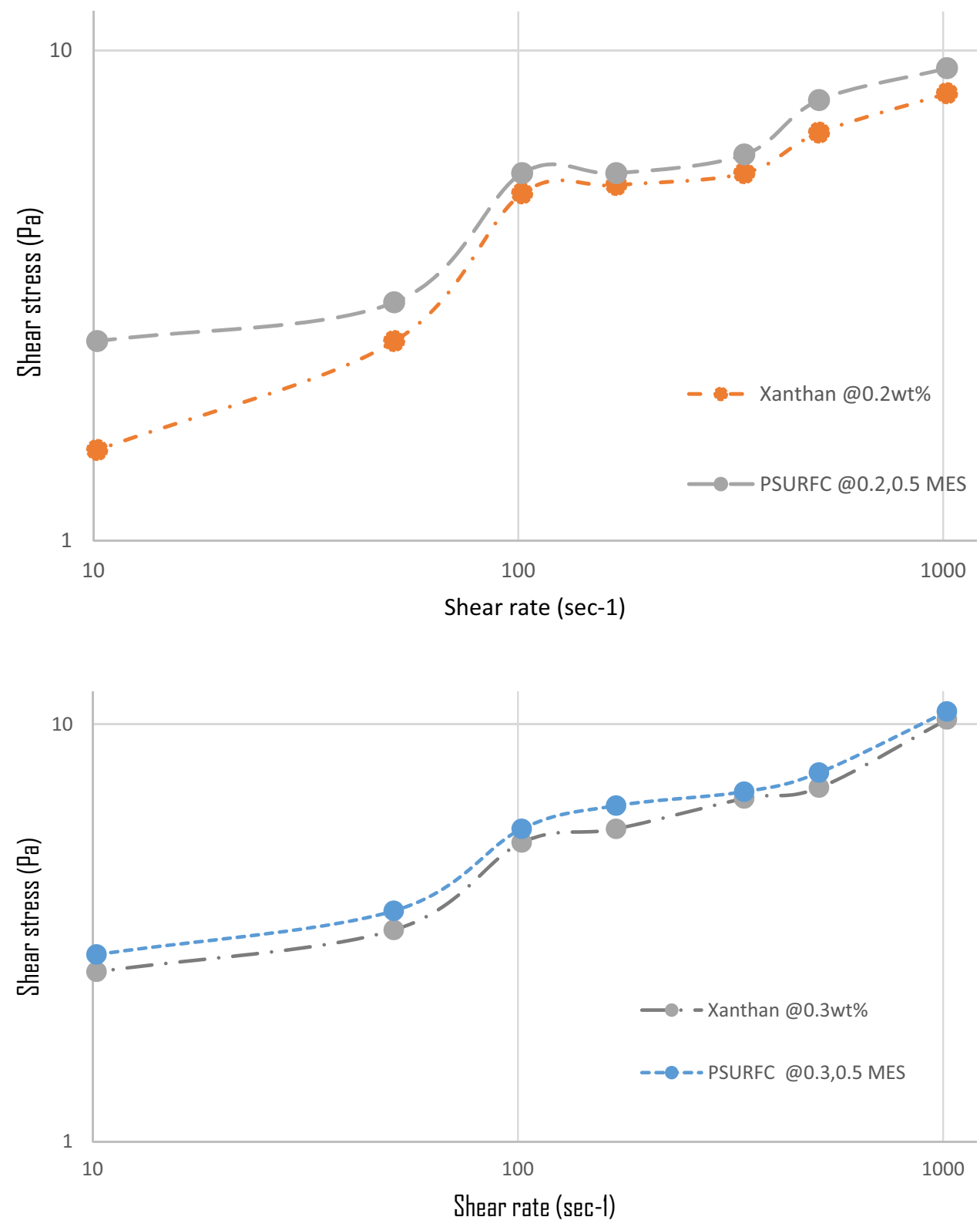
Fig. 4 Shear stress vs. shear rate analysis for Xanthan gum. Experimental condition: concentration@0.4wt\% and PSURFC concentration 3 [ @ $0.4 \mathrm{wt} \%$ Xanthan and $0.5 \mathrm{wt} \%$ surfactant]. Temperature at $28{ }^{\circ} \mathrm{C}$

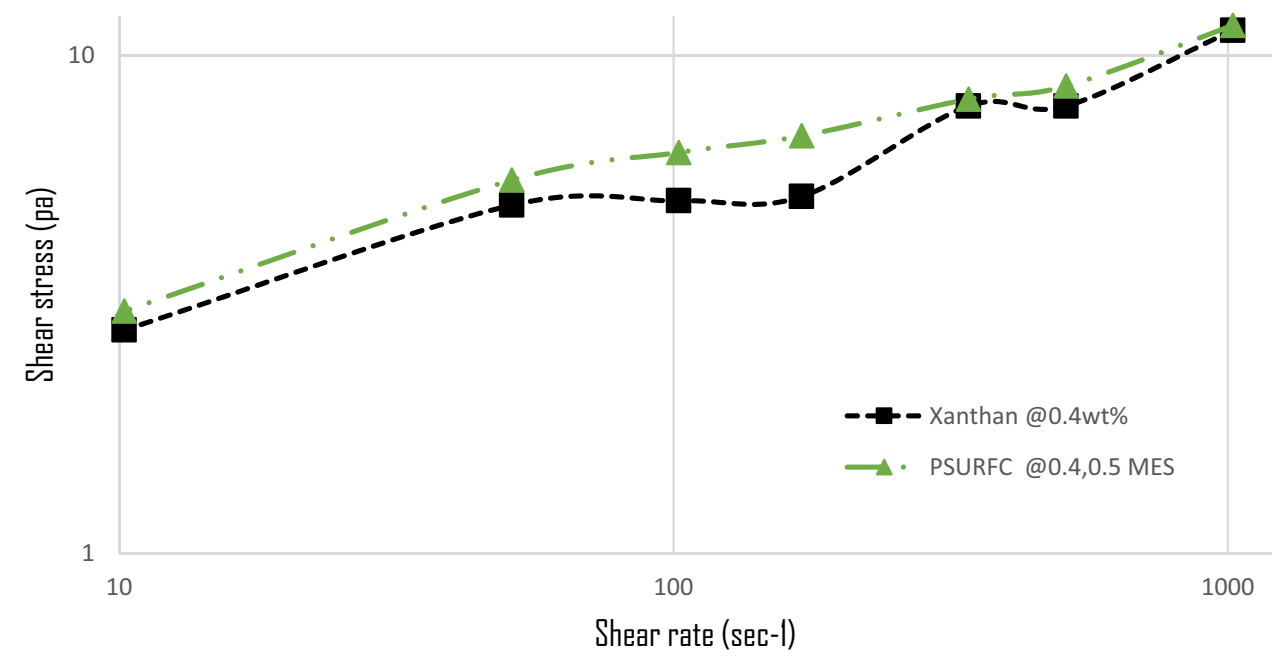

Fig. 5 Shear stress vs. shear rate analysis for Xanthan gum. Experimental condition: concentration@0.5wt\% and PSURFC concentration 4 [ @ $0.5 \mathrm{wt} \%$ Xanthan and 0.5wt\% surfactant]. Temperature at $28{ }^{\circ} \mathrm{C}$

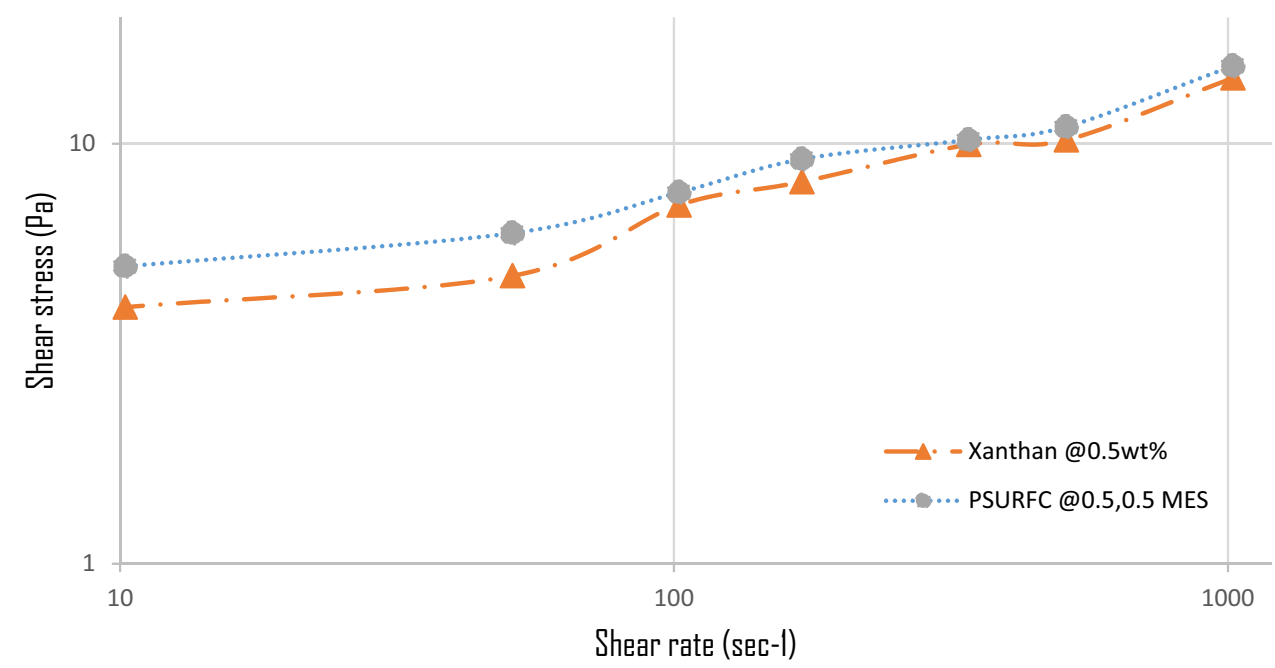

Table 4 Polymeric surfactant (PSURFC) concentrations

\begin{tabular}{lll}
\hline Polymer (Xanthan) & $\begin{array}{l}\text { Surfactant concentra- } \\
\text { tion }(\mathrm{ppm})\end{array}$ & (PSURFC) \\
\hline $0.2 \mathrm{wt} \%(1 \mathrm{~g})$ & $10,000 \mathrm{ppm}$ & Concentration 1 \\
$0.3 \mathrm{wt} \%(1.5 \mathrm{~g})$ & $10,000 \mathrm{ppm}$ & Concentration 2 \\
$0.4 \mathrm{wt} \%(2 \mathrm{~g})$ & $10,000 \mathrm{ppm}$ & Concentration 3 \\
$0.5 \mathrm{wt} \%(2.5 \mathrm{~g})$ & $10,000 \mathrm{ppm}$ & Concentration 4 \\
\hline
\end{tabular}

for improved residual oil recovery and enhanced production. Core flooding was conducted with OFITE's reservoir permeability tester (RPT). 100\% saturated core samples were initially displaced by oil at an injected rate of $1.5 \mathrm{cc} / \mathrm{min}$ to achieve initial water saturation $\mathrm{Sw}_{\mathrm{i}}$. Water flooding was done at the same conditions as the first recovery process to create the initial oil saturation state desired; afterward, various concentrations of the test fluids were injected at the rate $1.5 \mathrm{cc} / \mathrm{min}$. Samples of the effluent fluids were performed manually at 3-min interval aiding oil and brine measurement for saturation and recovery factor computation.

\section{Surfactant synthesis and formulation}

The conversion of non-edible seed oil extracted from Jatropha nuts constituted the formation of this bio-surfactant. Azman 2015 researched on the bio-surfactant production by the use of the fatty acid content in waste cooking oil to synthesize bio-surfactants. Sodium hydroxide was used as an alkaline base for the synthesis of the surfactant. Jatropha nuts were cleaned in water and air-dried, cut in small piece and the moistures were eradicated through vacuum process. Then, they were saturated in ethanol for $24 \mathrm{~h}$ and refluxed in ethanol for $48 \mathrm{~h}$. The subsequent blend was then cleaned, and the residue was distilled until all the ethanol was vaporized and high yield was observed during purification process. The residue was extracted using ethyl acetate 
and sodium sulfate. The extract was a gummy mass of Jatropha ready to be used as an anionic surfactant.

Saponification and acid value of the oil was calculated. $2 \mathrm{~g}$ of Jatropha oil was weighed into a 250-ml dry conical flask. $50 \mathrm{ml}$ of $0.5 \mathrm{M}$ alcoholic potassium hydroxide was measured and poured into the oil. A reflux condenser was fixed and heated to $50{ }^{\circ} \mathrm{C}$. It was allowed to reflux for an hour after which it was cooled. $50 \mathrm{~mL}$ of $0.5 \mathrm{M}$ potassium hydroxide was measured and dispensed in another $250-\mathrm{mL}$ dry round bottom flask and refluxed for an hour as well, without any oil in it, and allowed to cool. Both samples were then titrated. Table 2 presents the physicochemical properties of Jatropha oil.

The difference in the two titer values gives the number of hydrochloric acid required to neutralize the excess alkali.

The mixture of Jatropha oil, water and $\mathrm{NaOH}$ was done in a $500-\mathrm{mL}$ beaker equipped with a magnetic stirrer. For saponification reaction, a 500-ml glass reactor equipped
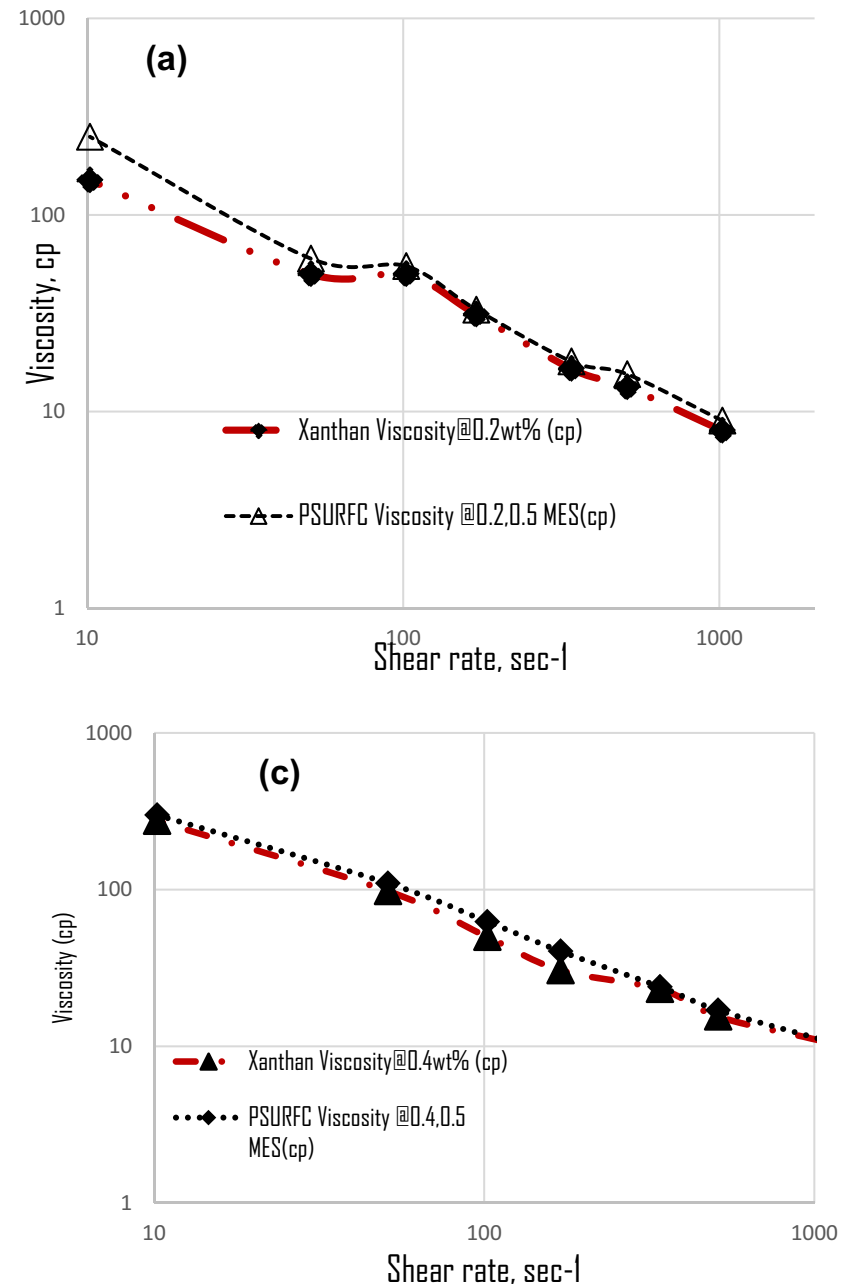

Fig. 6 Curves of polymer shear resistance of polymer and PSURFC solution. A slight change in the viscosity as in (a), (b), (c) and (d). Above displays an enhancement in polymer concentration on intro- with agitator was used in all experiments. The saponification reaction system was employed for the production of surfactants (Awang and Seng 2008). After the formation of surfactants (in form of detergents), the solubility of the synthesized surfactants was tested and Jatropha oil-based surfactants were observed to be extremely soluble in water. The formation of micelles was determined by a cloudy soapy water (Abraham and Orodu 2020). Nqobizitha and Sibanda (2015) stated that there were some observations about the effect of cloudiness of soap and concluded that the cloudier the soapy water, the more micelles are formed which shows. The surfactant solution was prepared by dissolving an appropriate amount of surfactant in $100 \mathrm{~mL}$ deionized water tabulated in Table 3. $\mathrm{pH}$ and concentrations were outlined also.

The criteria for selection majorly is based on $\mathrm{pH}$, cloudiness of soap and micelles formation. Table 3 illustrates the concentration and $\mathrm{pH}$ values of prepared surfactant.
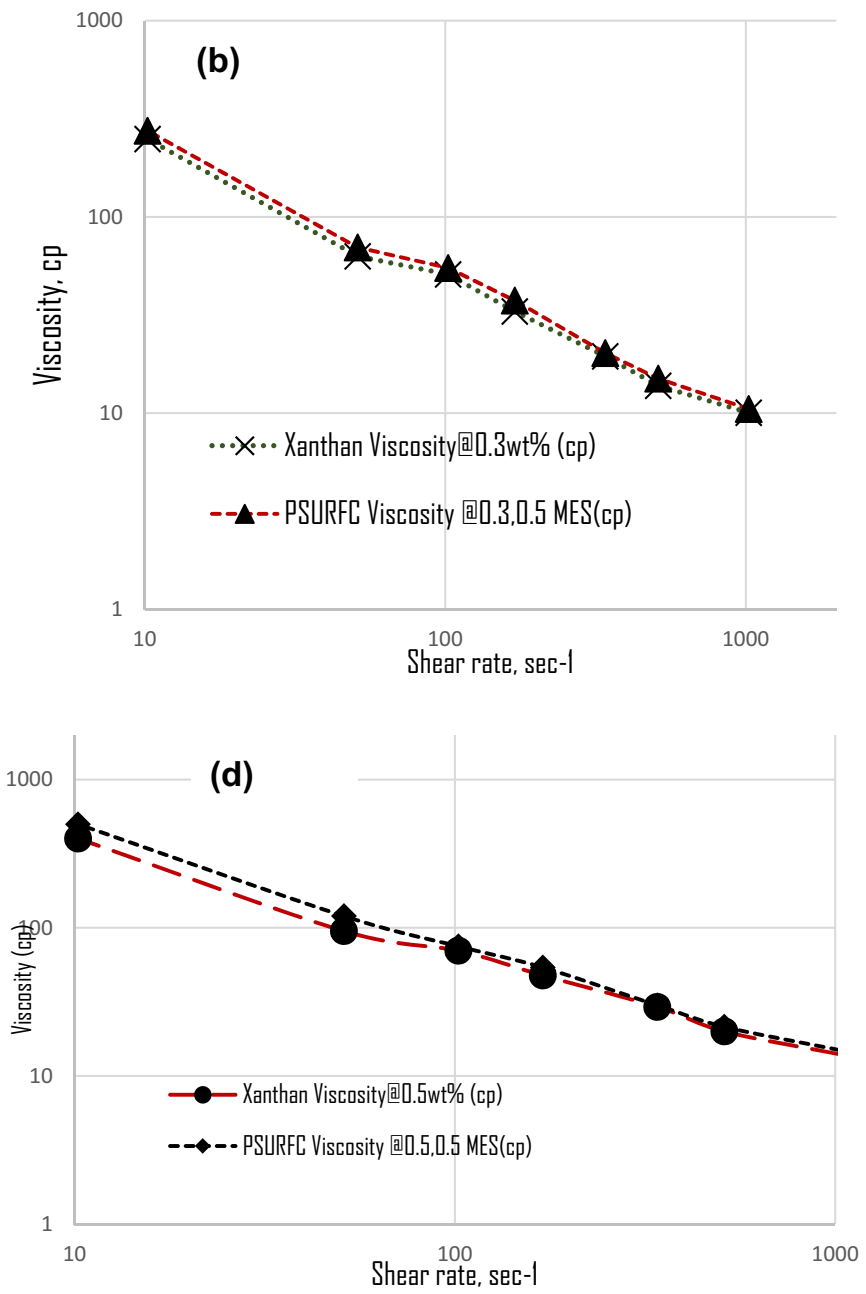

ducing surfactant. Reaction conditions: Polymer concentration varies from 0.2 to $0.5 \mathrm{wt} \%$ at $28{ }^{\circ} \mathrm{C}$ 
Fig. 7 Summary of rheological studies. Viscosity vs shear rate analysis for Xanthan gum and PSURFC. Experimental condition: concentration@ $0.2 \mathrm{wt} \%-0.5 \mathrm{wt} \%$ and PSURFC concentration 1-4 [@0.2-0.5 wt $\%$ Xanthan and $0.5 \mathrm{wt} \%$ surfactant]. Temperature $28^{\circ} \mathrm{C}$

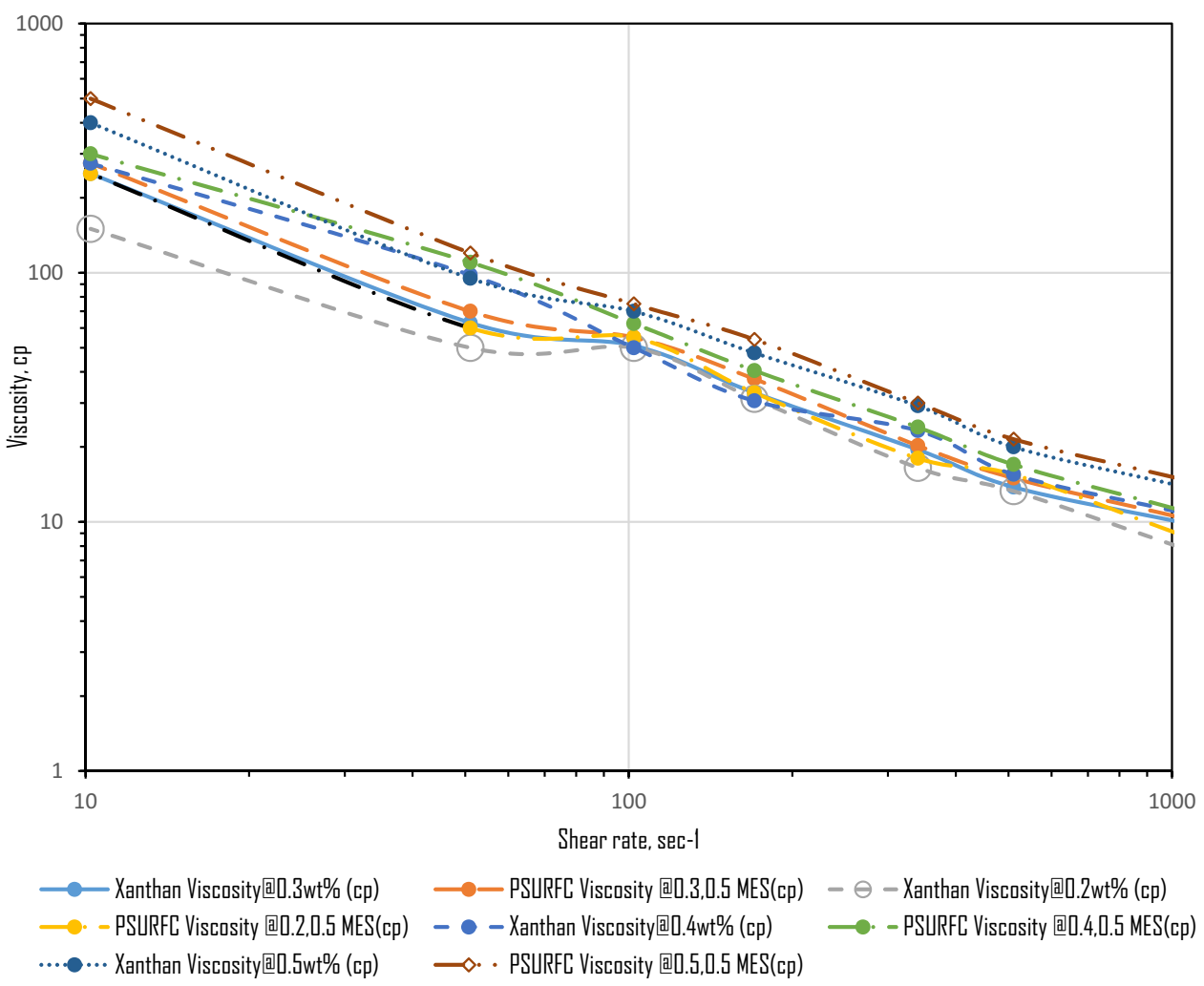

Table 5 Core flooding parameters and result for surfactant at different concentrations@0.2wt\% to $0.5 \mathrm{wt} \%$ for core A1

\begin{tabular}{lll}
\hline Core sample & Concentration & Oil recovery $(\%)$ \\
\hline Core A1 & Water & 21.23 \\
Core A1 & Surfactant at conc. 1 & 41.34 \\
Core A1 & Surfactant at conc. 2 & 49.72 \\
Core A1 & Surfactant at conc. 3 & 59.22 \\
\hline
\end{tabular}

Table 6 Core flooding parameters and result for surfactant at different concentrations at $0.2 \mathrm{wt} \%$ to $0.5 \mathrm{wt} \%$ for core B

\begin{tabular}{lll}
\hline Core sample & Concentration & Oil recovery $(\%)$ \\
\hline Core B & Water & 26.22 \\
Core B & Surfactant at conc. 1 & 37.20 \\
Core B & Surfactant at conc. 2 & 43.90 \\
Core B & Surfactant at conc. 3 & 57.93 \\
\hline
\end{tabular}

Nqobizitha and Sibanda (2015) stated that the higher the $\mathrm{pH}$ value of the surfactant, the better its washing ability nevertheless, and the $\mathrm{pH}$ value of the bio-surfactant should be well regulated as it has great effect on recovery as well as the condition of the reservoir after flooding. However, surfactant with the highest $\mathrm{pH}$ value (Lowest concentration) was employed in the formulating polymeric surfactant
(PSURFC), and this serves as the criteria for selecting the range of surfactant concentration. The extracted anionic surfactants from Jatropha oil satisfy the requirements of the oil industry that needs low adsorption and stable properties at high temperatures (Diyanti 2010; Azman 2015).

The polymer used in PSURFC preparation is Xanthan gum, a polysaccharide with both industrial and home usage (as a common food additive). Majorly, an increase in shear stress and temperature effect decreases polymer viscosity (Samanta and Ojha 2011). Similarly, increase in polymer weight increases the viscosity of polymer solution indicating the pseudoplastic fluid component of the polymer solution (Zheng and $\mathrm{Wu} 2020$ ).

However, as the weight of xanthan gum increased in the solution, the viscosity of xanthan gum solutions decreases with higher shear rates as shown in Fig. 2a, b, c and d and increased with lower shear stress in Figs. 2,3,4 and 5. This leads to shear thinning or pseudo-plasticity.

\section{Polymeric surfactant (PSURFC): preparation and synthesis}

Polymeric surfactants are macromolecules, which contain both hydrophilic and hydrophobic parts in their structure (Ma and Hao 2019). Compared to traditional surfactants, the macromolecular nature of these systems allows a much larger variety of structures. 
The $\mathrm{pH}$ and recovery potential of the surfactant serves as the criteria of selection for the surfactant solution mixed with the Xanthan gum solution to form PSURFC. The ability of surfactant to behave and perform as a dispersant, thickener, stabilizer and solubilizer enhanced the mixture.

The polymerization was conducted for $1.5 \mathrm{~h}$ using an auto-shaker water bath. Xanthan gum and surfactant solutions were prepared with $250 \mathrm{ml}$ distilled water using 500-ml round bottom flask, aged for 5 days at $70{ }^{\circ} \mathrm{C}$ temperature. The crude product was then extracted with acetone and dried in an oven at a temperature of $60{ }^{\circ} \mathrm{C}$ for $12 \mathrm{~h}$. Polymeric surfactant (PSURFC) was originated by the combinations listed below (Table 4).

\section{Results and discussion}

\section{Rheological behavior and viscosity of polymer and PSURFC solution}

Investigating rheological properties and viscosity is important to ascertain its effectiveness as an injectant during EOR. It also serves as a guideline for its implementation. Polymeric surfactants usually present very interesting rheological and interfacial properties (Elraies and Tan 2011).

Surfactant (MES) effects on the rheology of dispersions containing polymer in PSURFC showed relative stability in the viscosity of the dispersion. Also, a slight optimization in the rheological behavior of the PSURFC dispersion when compared to Xanthan in Figs. 6 and 7 could be tied to the associative interaction between polymer and surfactant. The associative interaction between the surfactant (MES) and polymer improves the gelling characteristics of the Xanthan gum.

The formulation and rheology of the injectants was performed at $28{ }^{\circ} \mathrm{C}$. Different concentrations of the polymer (Xanthan gum) were blended with fixed volume of surfactant (having the recommended $\mathrm{pH}$ value). The surfactant concentration was selected based on $\mathrm{pH}$ values as shown in Table 3 and recovery potential in Tables 5 and 6. The surfactants were tested on two different core samples and are graphically analyzed in Fig. 10. The significance of polymeric surfactant rheology for EOR is generally linked to the necessity of varying its mobility ratio by increasing the water phase viscosity (Zheng and Wu 2020). It was observed that the influence of increased percentage weight (0.2 wt \%, $0.3 \mathrm{wt} \%, 0.4 \mathrm{wt} \%$ and $0.5 \mathrm{wt} \%)$ causes changes in dial readings, thus affecting the viscosity of the two materials (Xanthan and PSURFC). The transition in fluid structure at shear rate of $\sim 1001 / \mathrm{s}$ resulted from a spontaneous reduction in shear stress as shear rate reduces. Also, a relative reduction at motor speed $\omega(\mathrm{r} / \mathrm{min})$ of 60 based on weight changes shows the point of yield stress (resulted into increment in viscosity). This point shows the viscous behavior at much lower shear rates. In Figs. 2, $3,4,5$, increment of viscosity resulted in reducing dial reading thereby influencing shear stress. Lower shear rate gave higher viscosity. The yield stress of PSURF indicates that the solution does not flow unless the applied stress exceeds a certain value.
Fig. 8 Interfacial tension (IFT) study of surfactant and polymeric surfactant at various concentration. Temperature $28{ }^{\circ} \mathrm{C}$

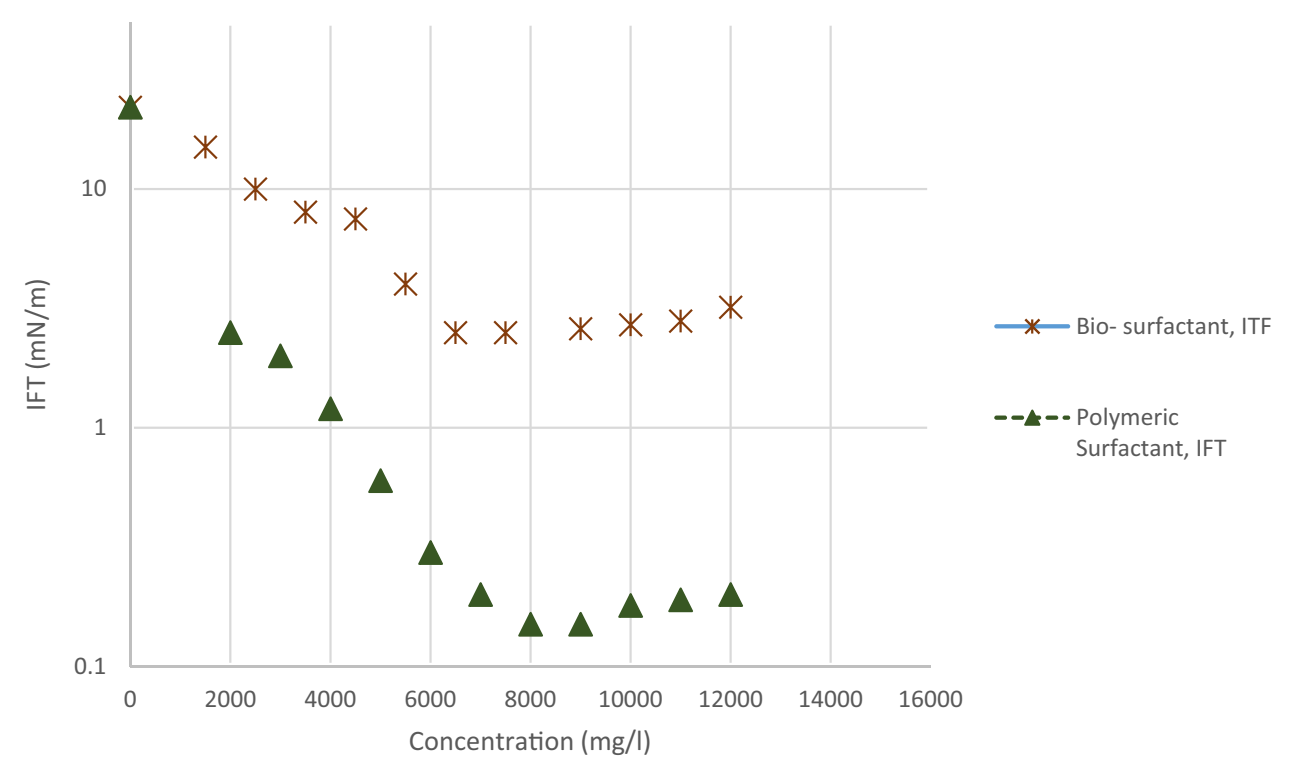


Fig. 9 Recovery potential of surfactant at different concentrations at $0.2 \mathrm{wt} \%$ to $0.5 \mathrm{wt} \%$ against time. Experimental condition: temperature at $28{ }^{\circ} \mathrm{C}$

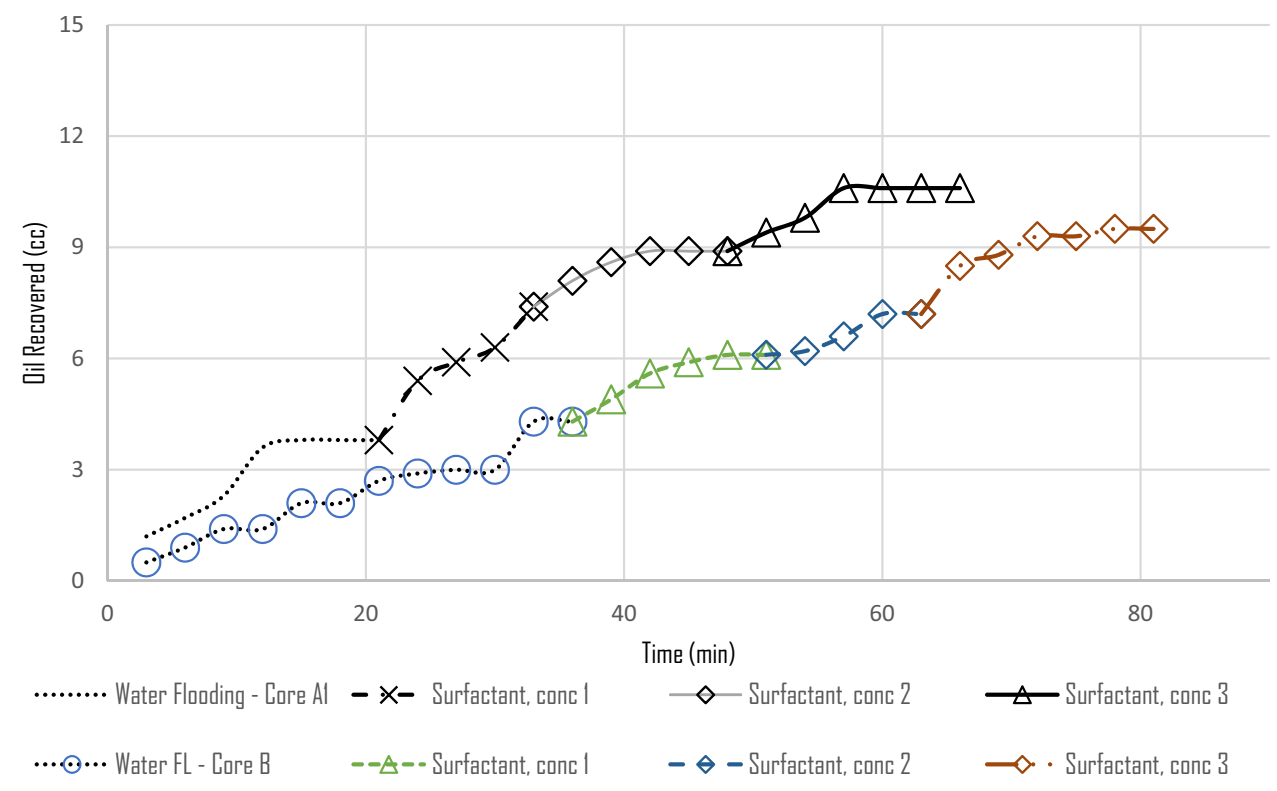

\section{IFT study of surfactant}

Figure 8 illustrates the comparison processes of the IFT between PSURFC, anionic Jatropha surfactant and crude oil solutions. IFT reduction is the best operative mechanism in surfactant flooding, and the study on this subject has been established (Manshad and Rezaei 2017).
However, dynamic equilibrium was observed between adsorption and desorption of surfactant molecules at oil-water interface resulting to a decreasing IFT to a minutest value. With increase in concentration of surfactant and polymeric surfactant, reduction in IFT was observed up to a minimum value known as CMC of the surfactant.
Fig. 10 Core flooding study comparison of water, surfactant and polymeric surfactant (PSURFC)

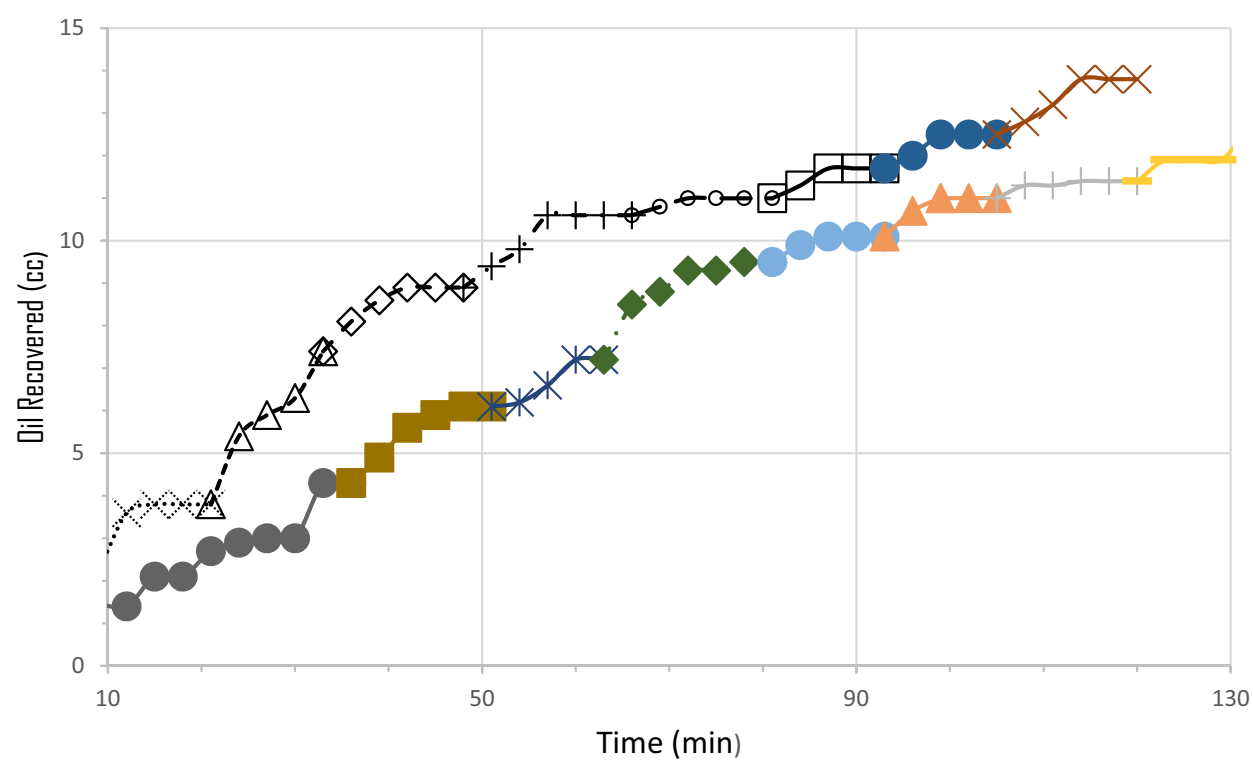

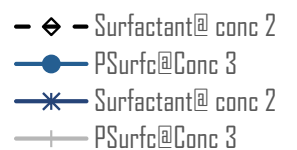

- +- Surfactant回 canc 3

$\longrightarrow$ PSurfe国Canc 4

- ४- Surfactant回 canc 3

- Surfactant回 conc $\rightarrow$ PSurfe国Canc 2 .

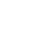


Core flooding study and comparison between water flooding and surfactant flooding at different concentration

Generally, wettability alteration and lowered IFT show a main part in the surfactant oil displacement process (Samanta et al. 2011). To examine the effects of surfactant concentration on oil mobilization to residual oil from reservoir-trapped oil, two bureau core samples were employed for the flooding process (Core A1 and Core B). The flooding was conducted using different surfactant concentrations, viz., surfactant at concentration 1 (Minimum), surfactant at concentration 2 and surfactant at concentration 3 (Optimum). Figure 9 shows an increase in oil recovery when surfactant concentration is increased from surfactant at concentration 1 to surfactant at concentration 3 . While there no incremental recovery was observed when higher concentrations were used, for this flooding process, the optimum concentration for this particular bio-surfactant is equal to surfactant at concentration 3 . This shows that the interfacial tension (IFT) had gotten to a low IFT between the reservoir fluids leading to a fixed value of oil recovered beyond this concentration of surfactant.

\section{Core flooding study comparison of water, surfactant and polymeric surfactant (PSURFC)}

To further investigate the effect of surfactant and polymer mixtures on oil recovery, the surfactant concentration that resulted in highest oil recovery from the core samples (surfactant at conc. 3) is mixed with polymer to form PSURFC.

Table 6 shows a summary of the total amount of oil recovered when various concentrations of surfactants were injected as a test fluid through the core flooding equipment (RPT). Maximum recovery was noticed as a result of synergic effects between mobility ratio and interfacial tension (IFT) by the PSURFC blend at an optimum of concentration 4 of PSURFC from Table 2 (Fig. 10).

\section{Core flooding using different concentrations of PSURFC to examine its recovery potential}

The result in Tables 7, 8 was generated from the outcome of flooding experiment performed using three core samples (Core C, Core D and Core E).

The test fluid was injected at a constant rate of $2.0 \mathrm{cc} / \mathrm{min}$ due to the thickness of the polymeric surfactant (PSURFC). The higher the concentration, the more recovery increases and the optimum concentration is concentration 4 .

However, beyond this concentration no additional recovery was noticed. This was due to the blockage of pore spaces 
Table 8 Core flooding parameters and result for water and formulated polymeric PSURFC flooding @ $28 \mathrm{C}$

\begin{tabular}{|c|c|c|c|c|c|c|}
\hline Core sample & Pore volume (cc) & $\mathrm{Sw}_{\mathrm{i}}$ & Water flooding (cc) & PSURFC conc $1(\mathrm{cc})$ & PSURFC conc $2(\mathrm{cc})$ & $\begin{array}{l}\text { PSURFC } \\
\text { conc } 3 \\
\text { (cc) }\end{array}$ \\
\hline Core $\mathrm{C}$ & 19 & 0.23 & 5.5 & 10.5 & 11.02 & 12.16 \\
\hline Core D & 9 & 0.18 & 6.1 & 4.68 & 5.5 & 5.4 \\
\hline Core E & 10.9 & 0.2 & 2.9 & 6 & 6.5 & 6.8 \\
\hline Core G & 11.5 & 0.21 & 3.4 & 6.2 & 6.21 & 7 \\
\hline \multicolumn{7}{|l|}{$\%$ Recovery } \\
\hline \multicolumn{7}{|l|}{ Incremental recovery } \\
\hline Post PSURFC conc 1 & & \multicolumn{2}{|c|}{ Post PSURFC @ conc 2} & \multicolumn{2}{|c|}{ Post PSURFC @conc 3} & $\begin{array}{l}\text { Post } \\
\text { PSURFC } \\
\text { @ conc } 4\end{array}$ \\
\hline $53 \%$ & & \multicolumn{2}{|l|}{$58 \%$} & \multicolumn{2}{|l|}{$64 \%$} & $69 \%$ \\
\hline $51 \%$ & & \multicolumn{2}{|l|}{$61 \%$} & \multicolumn{2}{|l|}{$60 \%$} & $64 \%$ \\
\hline $54 \%$ & & \multicolumn{2}{|l|}{$60 \%$} & \multicolumn{2}{|l|}{$62 \%$} & $68 \%$ \\
\hline $49 \%$ & & \multicolumn{2}{|l|}{$54 \%$} & \multicolumn{2}{|l|}{$61 \%$} & $66 \%$ \\
\hline
\end{tabular}

as a result of the increase in the molecular weight of the polymeric surfactant (Fig. 11).

\section{Scanning electron microscopy (SEM) analysis of PSURFTC}

The SEM analysis for the effect of polymeric surfactant on core sample is shown in Fig. 12a, b, c, and d. In Fig. 12a, due to low concentration of PSURFTC at $0.2 \mathrm{wt} \%$ on core sample, the absorption rate was low resulting into small accumulation on the pore interface. The mass of polymer was at its lowest concentration at this point. By physical examination of the core, shapes of pore spaces look clearer and sharper with few whitish appearances indicating more space for fluid flow. Figure 12b shows that at PSURFTC [0.3 wt \%], the influence of concentration of polymeric surfactant gradually increases leaving more traces, the whitish appearance on the core increases and the pore space is gradually closing as a result of accumulations from absorption on the pore interface. Figure 12c, of PSURFTC [0.4 wt\%], shows the impact of concentration of polymeric surfactant progressively increases due to increased polymer mass. At certain point in the flooding process, the mass of polymer increased and the piston like displacement process leads to increased oil production and ceased when accumulated mass increased.

PSURFTC at $0.5 \mathrm{wt} \%$ from Fig. $12 \mathrm{~d}$ shows that the effect of concentration of polymeric surfactant was at highest and gradually increases leaving more accumulation and absorption on the pore interface. Figure 11 illustrates the recovery effect translated from the result of this SEM analysis. The accumulated oil recovery stopped at $0.5 \mathrm{wt} \%$ resulting from the variation in retention as a result of concentration of the anionic polymeric surfactants. This leads to a blockage in pore space leading to fixed recovery as injected wt $\%$ increases. Any concentration greater than this did not increase recovery.

There were some limitations encountered during the experiment, some of which were the calibration of the RPT to minimize the error of values generated. The errors in the viscosity measurements are less than $0.003 \mathrm{mPa} . \mathrm{s}$, and the percentage oil recovery errors were less than \pm 1 . The errors from the core flooding parameters and result for Water and various concentrations of surfactant flooding at $28 \mathrm{C}$ were less than 0.01 . Blockage of core samples was noticed at higher concentrations of the mixture this lead to reduced or not recovery at concentrations higher that the ones used in this work.

\section{Conclusion}

Polymeric surfactant combines the high-viscosity polymer with the interfacial property of a bio-based surfactant reducing the tension at water/oil interface and enhancing 
the viscosity of the aqueous solution simultaneously. The ability of polymeric surfactant used in this work was tested on a porous media, and the core samples were checked for their physical properties to assume a perfect reservoir condition. Shear-thinning behavior was observed at room temperature $\left(28^{\circ} \mathrm{C}\right)$ and an improvement in rheology on addition of surfactant to the mixture. The recovery effect was translated from the result of SEM analysis. Accumulated oil recovery stopped at $0.5 \mathrm{wt} \%$ resulting from the variation in retention as a result of concentration of the anionic polymeric surfactants, which may result to a blockage in pore space leading to fixed recovery as injected wt $\%$ increases. Any concentration greater than this did not increase recovery. When concentrations of PSURFC were applied during core flooding process, there was an incremental recovery from $50-70 \%$ of the initial oil in place sequel to the conventional water flooding process.

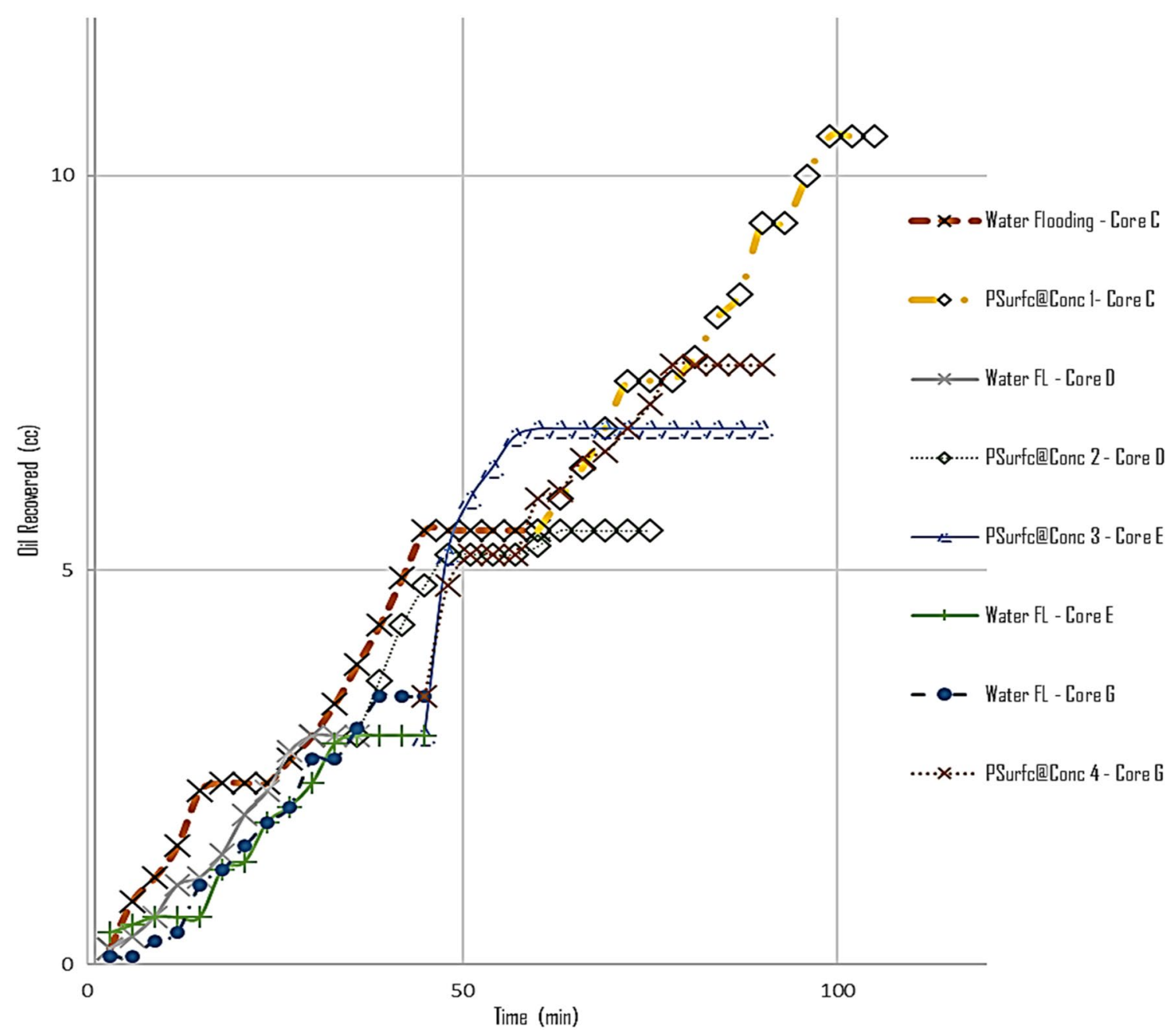

Fig. 11 Flooding experiment performed using three core samples (Core C, Core D and Core E) at different PSURFC concentrations: experimental condition: flooding temperature at $28^{\circ} \mathrm{C}$, constant rate of $2.0 \mathrm{cc} / \mathrm{min}$ 

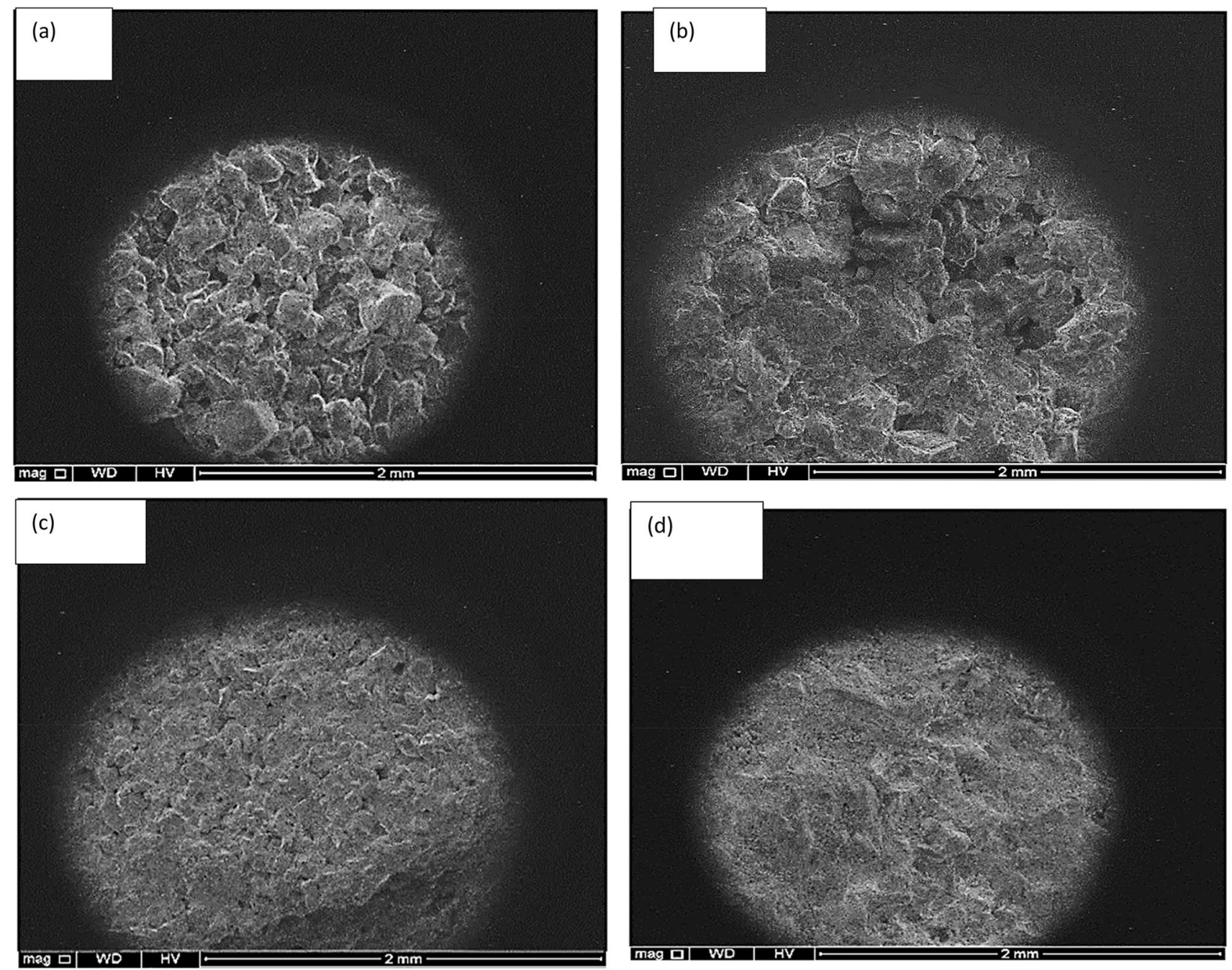

Fig. 12 SEM analysis of PSURFTC

Acknowledgements The authors would like to thank the management of Covenant University for providing the needed facilities to carry out this research.

\section{Compliance with ethical standards}

Conflict of interest The authors have no conflict of interest to declare.

Open Access This article is licensed under a Creative Commons Attribution 4.0 International License, which permits use, sharing, adaptation, distribution and reproduction in any medium or format, as long as you give appropriate credit to the original author(s) and the source, provide a link to the Creative Commons licence, and indicate if changes were made. The images or other third party material in this article are included in the article's Creative Commons licence, unless indicated otherwise in a credit line to the material. If material is not included in the article's Creative Commons licence and your intended use is not permitted by statutory regulation or exceeds the permitted use, you will need to obtain permission directly from the copyright holder. To view a copy of this licence, visit http://creativecommons.org/licenses/by/4.0/.

\section{References}

Abraham DV, Orodu OD (2020) The influence of surfactant concentration and surfactant type on the interfacial tension of heavy crude oil/brine/surfactant system. Petrol Coal 62:292-298

Agrawal A, Satapathy A (2019) Thermal, mechanical, and dielectric properties of aluminium oxide and solid glass microsphere-reinforced epoxy composite for electronic packaging application. Polym Compos 9:2573-2581

Al-Manasir N, Kjøniksen A-L (2009) Preparation and characterization of cross-linked polymeric nanoparticles for enhanced oil recovery applications. Wiley, Amsterdam

Alvani A, Jouyban A (2019) The effect of surfactant and polymer on solution stability and solubility of tadalafil-methylparaben cocrystal. J Mol Liq 281:86-92

Awang M, Seng GM (2008) Sulfonation of phenols extracted from the pyrolysis oil of oil palm shells for enhanced oil recovery. Chemsuschem 1:210-214

Azman NA (2015) Bio-surfactant syhnthesis from waste. Faculty Of Chemical \& Natural Resources Engineering, Malaysia 
Banerjee S, Kumar R (2015) Effect of natural and synthetic surfactant on the rheology of light crude oil. Taylor \& Francis Group, LLC, Abingdon, pp 1516-1525

Belhaj AF, Elraies KA (2020) The efect of surfactant concentration, salinity, temperature, and $\mathrm{pH}$ on surfactant adsorption for chemical enhanced oil recovery: a review. J Petrol Explor Prod Technol 10:125-137

Bera A, Belhaj H (2016) Ionic liquids as alternatives of surfactants in enhanced oil recovery-a state-of-the-art review. J Mol Liq 224:177-188

Chen L, Zhang G (2013) Research of the heavy oil displacement mechanism by using alkaline/surfactant flooding system. Colloids Surf A Physicochem Eng Asp 434:63-71

Coolman T, Alexander D (2020) An evaluation of the enhanced oil recovery potential of the xanthan gum and aquagel in a heavy oil reservoir in Trinidad. J Petrol Explor Prod Technol

Diyanti AA (2010) The production of surfactant by direct reaction of pyrolysis oil for enhanced oil recovery. Taylor \& Francis Group, LLC, Abingdon, pp 1540-1546

Elraies KA, Tan IMJ (2011) Development of a new polymeric surfactant for chemical enhanced oil recovery. Petrol Sci Technol 29:1521-1528

Hanamertani AS (2017) Ionic liquids as a potential additive for reducing surfactant adsorption onto crushed berea sandstone. J Petrol Sci Eng 11:480-490

Hirasaki G, Miller CA, Puerto M (2013) Recent advances in surfactant EOR. SPE J 16(4):889-907

Lee EM, Koopal LK (1996) Adsorption of cationic and anionic surfactants on metal oxide surfaces: surface charge adjustment and competition effects. J Colloid Interface Sci 12:478-489

LuukKoopal KEM (1995) Adsorption of cationic and anionic surfactants on charged metal oxide surfaces. J Colloid Interface Sci 13:85-97

Ma Y, Hao J (2019) Biobased polymeric surfactant: natural glycyrrhizic acid-appended homopolymer with multiple ph-responsiveness. J Colloid Interface Sci 541:93-100

Mahfud R, Agag T (2013) Synthesis and evaluation of novel anionic polymeric surfactants based on polybenzoxazines. J Colloid Interface Sci 407:339-347

Manshad AK, Rezaei M (2017) Wettability alteration and interfacial tension (IFT) reduction in enhanced oil recovery (EOR) process with ionic liquid flooding. J Mol Liq 248:153-162

Mozaffari S, Li W (2018) Ligand-mediated nucleation and growth of palladium metal nanoparticles. J Vis Exp 136:e57667

Mozaffari S, Tchoukov P (2015) Effect of asphaltenes aggregation on rheological properties of diluted athabasca bitumen. Energy Fuels 29:5595-5599

Ojo T, Fadairo A (2017) Effect of jatropha bio-surfactant on residual oil during enhanced oil recovery process. Int J Appl Eng Res 12(20):10036-10042
Orodu KB, Afolabi RO (2019) Effect of aluminum oxide nanoparticles on the rheology and stability of a biopolymer for enhanced oil recovery. J Mol Liq 288:0167-7322

Rabiei A, Sharifinik M (2013) Core flooding tests to investigate the effects of ift reduction and wettability alteration on oil recovery during meor process in an iranian oil reservoir. Appl Microb Cell Physiol 97:5979-5991

Radnia H, Rashidi A (2018) A novel nanofluid based on sulfonated graphene for enhanced oil recovery. J Mol Liq 271:795-806

Rashidi MM, Keimanesh M (2010) Using differential transform method and padé approximant for solving MHD flow in a laminar liquid film from a horizontal stretching surface. Math Probl Eng 2010:1-14

Samanta A, Ojha K (2011) Surfactant and surfactant-polymer flooding for enhanced oil recovery. Adv Petrol Explor Dev 2:13-18

Samanta A, Ojha K, Sarkar A, Mandal A (2011) Surfactant and surfactant-polymer flooding for enhanced oil recovery. Adv Petrol Explor Dev 2:13-18

Saxena N, Kumar S (2018) Adsorption characteristics and kinetics of synthesized anionic surfactant and polymeric surfactant on sand surface for application in enhanced oil recovery. Asia-Pac J Chem Eng 13:e2211

Saxena N, Saxena A (2019) Synthesis, characterization and enhanced oil recovery potential analysis through simulation of a natural anionic surfactant. J Mol Liq 282:545-556

Souayeh M, Al-Wahaibi Y, Al-Bahry S, Elshafie A, Al-Bemani A, Joshi S, Al-Hashmi A, Al-Mandhari M (2014) Optimization of a low-concentration strain biosurfactant toward microbial enhanced oil recovery. Energy Fuels 28(9):5606-5611

Temiloluwa O, Adesina F (2017) Effect of jatropha bio-surfactant on residual oil during enhanced oil recovery process. Int J Appl Eng Res 10036-10042

Temiouwa O, Oluwaanmi O (2018) Nano augumented biosurfactant formulation for oil recovery in medium oil reservoirs. In: SPE, NAICE conference. SPE, Lagos, pp 1-10

Wever DAZ, Picchioni F, Broekhuis AA (2011) Polymers for enhanced oil recovery: a paradigm for structure-property relationship in aqueous solution. Prog Polym Sci 36(11):1558-1628

Zheng W, Wu X (2020) Impact of polymer addition, electrolyte, clay and antioxidant on rheological properties of polymer fuid at high temperature and high pressure. J Petrol Explor Prod Technol 10:663-671

Publisher's Note Springer Nature remains neutral with regard to jurisdictional claims in published maps and institutional affiliations. 